\title{
Changes in bone mineral density of the distal femur after revision total knee arthroplasty with metaphyseal press-fit stem
}

\author{
Claus L. Jensen • Michael M. Petersen • \\ Henrik M. Schrøder $\cdot$ Bjarne Lund
}

Received: 8 December 2009/Accepted: 28 June 2010/Published online: 15 July 2010

(c) The Author(s) 2010. This article is published with open access at Springerlink.com

\begin{abstract}
Background The effect of postoperative adaptive bone remodeling following a stemmed femoral implant in revision total knee arthroplasty (rTKA) is unknown. The aim of this study was to evaluate bone mineral density (BMD) changes of the distal femur following cemented rTKA with a $100-\mathrm{mm}$ press-fit stem.

Materials and methods Sixteen consecutive patients were included in the study (age range 40-85 years; mean 63.5 years). $\operatorname{NexGen}^{\circledR}$ (Zimmer, Warsaw, IN, USA) cemented revision implants were used. All implants had the same press-fit femoral stem length of $100 \mathrm{~mm}$. Clinical examinations with evaluation of the knee function using the Knee Society's Knee Scoring System were used. Measurements of BMD $\left(\mathrm{g} / \mathrm{cm}^{2}\right)$ were performed by dualenergy X-ray absorptiometry (DEXA) using a Norland XR-46 (Norland Corp. Fort Atkinson, WI, USA) bone densitometer.

Results Knee and function scores improved significantly $(P=0.005)$ from the preoperative values to 1 year of follow-up. In regions of interest (ROI) $1-4$, a significant increase in BMD (3.5-6.0\%) after 6 months was seen. This increase only remained significant in ROI $4(4.0 \%, P=0.01)$ at 1 year of follow-up.

Conclusions The increase in BMD is probably the result of increased mobility and load on the extremity after implantation of a well-functioning rTKA.
\end{abstract}

C. L. Jensen $(\varangle) \cdot$ M. M. Petersen · H. M. Schrøder · B. Lund Department of Orthopaedic Surgery U,

University of Copenhagen, Rigshospitalet,

Blegdamsvej 9, 2100 København Ø, Denmark

e-mail: clindkaer@gmail.com
Keywords DEXA - BMD - Distal femur .

Revision total knee arthroplasty

\section{Introduction}

Operation with implantation of a primary total knee arthroplasty (TKA) or a revision total knee arthroplasty (rTKA) represents a significant trauma to the bone and soft tissue of the affected extremity. It is well known that various traumatic conditions of an extremity can induce bone loss in most patients [1]. In TKA or rTKA, other factors such as stress shielding, wear-debris-induced osteolysis, implant loosening, and bone necrosis due to infection can also play an important role in bone loss, and removal of implants during revision knee surgery can even worsen existing bone loss. Dual energy X-ray absorptiometry (DEXA) [2,3] can be used to measure changes in bone mineral density (BMD) close to an orthopedic implant. The effect of postoperative adaptive bone remodeling with a stemmed femoral implant in rTKA is unknown. Several studies on BMD changes of the distal femur after TKA exist. A common finding is a decrease in BMD from baseline up to 2 years after operation [4-7]. No studies on BMD changes of the femur after rTKA have previously been published. The aim of this study was to evaluate BMD changes of the distal femur following cemented rTKA with a $100-\mathrm{mm}$ press-fit stem.

\section{Materials and methods}

Sixteen consecutive patients with rTKA were included in a study with the aim of measuring adaptive bone remodelling around a stemmed revision femoral implant. There were 
nine men and seven women with a mean BMI of 28 (21-39) and a mean age of 63.5 (range 40-85) years (Table 1). All patients received NexGen ${ }^{\circledR}$ (Zimmer, Warsaw, IN, USA) cemented revision implants (Fig. 1), and either Legacy ${ }^{\circledR}$ knee-constrained condylar $(n=12)$ or Legacy ${ }^{\circledR}$ knee-posterior stabilized $(n=4)$ knees were inserted (Table 1). All implants had the same press-fit femoral stem length of $100 \mathrm{~mm}$ (with or without offset), with stem diameter ranging from 15 to $24 \mathrm{~mm}$ (average $18.5 \mathrm{~mm}$ ). The patients also participated in a randomised study of 40 patients with the aim of evaluating the use of trabecular metal cones (Zimmer) for reconstruction of considerable bone loss of the proximal tibia in rTKA. The Anderson Orthopaedic Research Institute (AORI) Bone Defect Classification [8, 9] was used to classify bone loss of the distal femur. All patients had type F2b defects (Table 1). Primary osteoarthritis was the major primary disease leading to the first TKA (Table 1). Eight patients were revised because of aseptic loosening, four because of instability, one because of polyethylene (PE) wear, and three because of deep infection. The same surgeon performed all operations. Clinical examination with evaluation of knee function using the Knee Society's Knee Scoring System [10] were performed preoperatively and with follow-up after 1 year. All patients gave informed consent prior to the study, which was authorized by the local Scientific Ethical Committee of Københavns and Frederiksberg Kommuner (KF 01 276195) and was performed in accordance with the ethical standards of the 1964 Declaration of Helsinki as revised in 2000.

BMD measurements $\left(\mathrm{g} / \mathrm{cm}^{2}\right)$ were performed by DEXA using a Norland XR-46 (Norland) bone densitometer. All measurements were performed in the coronal plane of the limb with a scan speed of $45 \mathrm{~mm} / \mathrm{s}$ using the research scan option. Scans were performed of the distal femur and along the femoral shaft in close relation to the femoral component (pixel size $1.0 \mathrm{~mm} \times 1.0 \mathrm{~mm}$ ). Furthermore, scans of the distal tibia and fibula just above the ankle joint were performed bilaterally (pixel size $0.5 \times 0.5 \mathrm{~mm}$ ). All scans were performed with patients lying flat on their back, the knee extended, and the ankle in a neutral position with the toes pointing straight up. All patients had their first scans performed within the first 2 weeks after surgery and with follow-up after 3, 6, and 12 months. Custom-made software was used to analyze DEXA scans [11] that allows BMD measurement in close relation to orthopedic implants by excluding pixels considered by the software as metal and allows a variable metal exclusion threshold to be set by the physician. The metal exclusion threshold was set at $4.5 \mathrm{~g} / \mathrm{cm}^{2}$. On the computerized scan plots, five regions of interest (ROI) were selected to measure BMD of the distal femur and femoral shaft. The femur stem was divided into three ROIs of the same size: distal (ROI 1), intermediate
Table 1 Demographic, clinical, and operative data

\begin{tabular}{ll}
\hline Patient characteristics & Corresponding statistics \\
\hline Number & 16 \\
Age (years) & $63.5(40-85)$ \\
Sex (M/F) & $9 / 7$ \\
Body mass index & $28(21-39)$ \\
Primary disease & \\
Primary arthrosis & 11 \\
Secondary arthrosis & 3 \\
Haemofilia & 2 \\
Prothesis type & 12 \\
Constrained condylar & 4 \\
Posterior stabilized & \\
Femur implant & 100 \\
Stem length (mm) & $18.5(15-24)$ \\
Stem diameter (mm) & $37(0-70)$ \\
Numbers of used femur augments per patient \\
0 \\
1
\end{tabular}

PE polyethylene, AORI Anderson Orthopaedic Research Institute

(ROI 2), and a proximal (ROI 3). ROI 4 was defined as a total the three ROIs. At the tip of the stem, a distal ROI was defined as ROI 5 (Fig. 2). In the distal tibia and fibula, one ROI was selected $1 \mathrm{~cm}$ above the ankle joint line.

Statistical analysis

Changes in BMD are given as the mean percentage change together with total range and standard deviation (SD). For evaluation, $t$ test for paired data with calculation of the $95 \%$ confidence intervals $(95 \% \mathrm{CI})$ were performed, and $P$ values $<0.05$ were considered significant. 


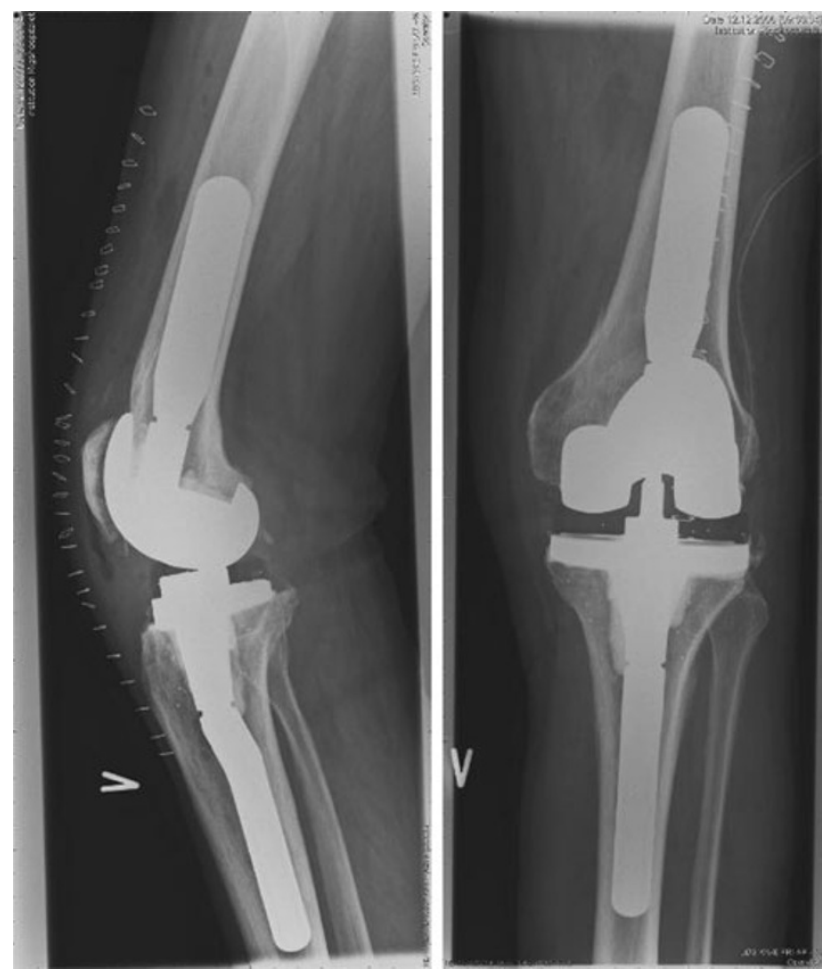

Fig. 1 Cemented revision total knee arthroplasty (rTKA) with a Legacy ${ }^{\circledR}$ knee-constrained condylar implant with a 100 -mm press-fit stem
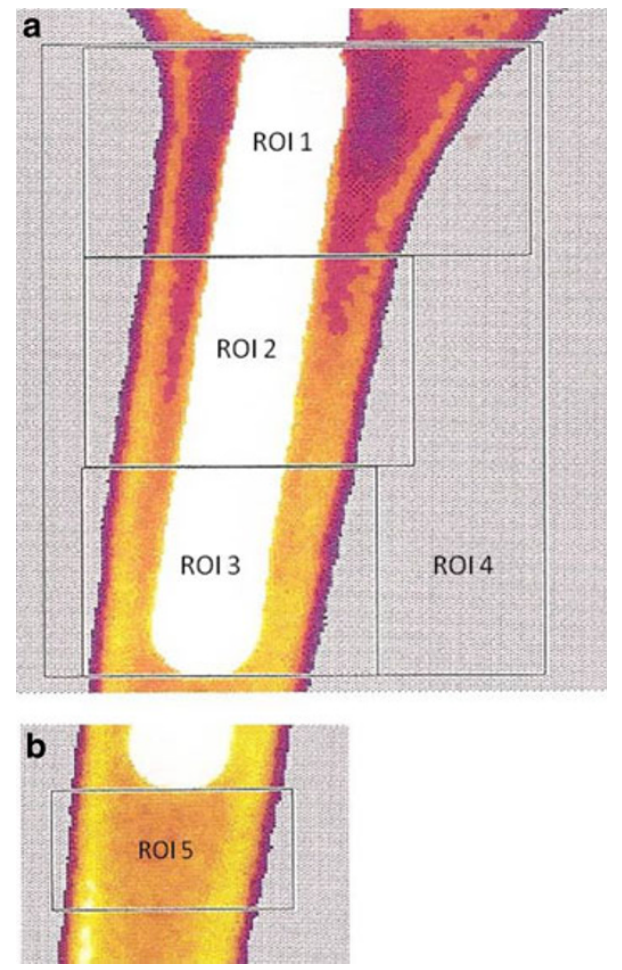

Fig. 2 Dual-energy X-ray absorptiometry (DEXA) scan plots of the distal femur showing the four regions of interest (ROIs). along the stem (a) and the fifth at the tip of the stem (b)

\section{Results}

Knee and function scores improved significantly $(P=0.005)$ from the preoperative values of 37 and 24 to 78 and 61 at 1 year of follow-up. In ROIs $1-4$, a significant increase in BMD reaching 3.5-6.0\% after 6 months was seen during the first 3-6 months after surgery. This increase only remained significant in ROI $4(4.0 \%, P=0.01)$ at 1 year of follow-up (Table 2). In ROI 5, no significant changes was observed during the first postoperative year. BMD changes of the distal tibia showed a temporary decrease of $4.4 \%(P=0.03)$ in the operated legs, but this increase was not significant at the 1-year follow-up. In the contralateral distal tibia, no significant changes in BMD were seen (Table 2).

\section{Discussion}

Clinical outcome after 1 year of follow-up was comparable with other studies on rTKA with considerable bone loss, where bone loss at the proximal tibia and/or femur was reconstructed with stemmed femoral implants and impaction bone grafting $[12,13]$ with or without metal augments [14]. We found at 6 months of follow-up a significant increase in BMD of 3.5-6\% in all ROI along the stem. However, after 1 year, the increase (4\%) in BMD was only significant in ROI 4. In ROI 5 above the stem, no significant changes in BMD were observed.

To our knowledge there exists no published studies on BMD changes at the distal femur after rTKA. Existing knowledge comes from finite element studies on stemmed femoral implants and studies evaluating changes in BMD around the femoral component without stem after TKA. In a finite element study, Van Lenthe et al. [15] studied bone loss and remodelling patterns of four femoral components: two primary TKAs and two stemmed revision prostheses with stem diameter of, respectively, 18 and $12 \mathrm{~mm}$. They found that the revision prostheses tended to cause more bone loss than the primary implants, especially in the distal regions. They also found that prostheses with a thick pressfit stem comparable with the implants in our study would be expected to lead to an increased bone loss of the most distal femur due to increased stress shielding. However, in the ROI proximally along the stem comparable with the ROI used in this study, they found stresses and strains slightly higher than in the femur without TKA or rTKA and thus predicted minimal increase in BMD in the most proximal ROI.

Our results are consistent with the findings made by Van Lenthe et al. [15]. We believe that the increase in BMD along the proximal parts of the femoral stem was caused by an increase in strain created by altered mechanical load. This remodelling of the periprosthetic bone is well known 
Table 2 Bone mineral density (BMD) changes in the distal tibia of the operated [revision total knee arthroplasty (rTKA)] and contralateral legs

$P$ unpaired and paired Student's $t$ test, $S D$ standard deviation, CI confidence interval

Table 3 Changes in bone mineral density (BMD) of the distal femur around the revision total knee arthroplasty (rTKA)

\begin{tabular}{|c|c|c|c|c|c|c|c|}
\hline ROI & $\begin{array}{l}\text { BMD }\left(\mathrm{g} / \mathrm{cm}^{2}\right) \\
\text { Post }\end{array}$ & $\begin{array}{l}\Delta \text { BMD (\%) } \\
0-3 \text { months }\end{array}$ & $P$ value & $\begin{array}{l}\Delta \text { BMD (\%) } \\
0-6 \text { months }\end{array}$ & $P$ value & $\begin{array}{l}\Delta \text { BMD }(\%) \\
0-12 \text { months }\end{array}$ & $P$ value \\
\hline \multicolumn{8}{|l|}{ Operated } \\
\hline Mean & 0.693 & -2.5 & & -4.4 & & -1.3 & \\
\hline Range & $0.184-1.032$ & -24.1 to 11.4 & & -17.6 to 3.3 & & -16.3 to 12.3 & \\
\hline SD & 0.23 & 9.5 & & 5.6 & & 7.7 & \\
\hline $95 \% \mathrm{CI}$ & & $-8.2 ; 3.2$ & 0.39 & $-7.8 ;-1.1$ & 0.03 & $-5.7 ; 3.2$ & 0.39 \\
\hline \multicolumn{8}{|c|}{ Not operated } \\
\hline Mean & 0.678 & -1.6 & & 1.84 & & 1.6 & \\
\hline Range & $0.284-1.024$ & -18.5 to 12.6 & & -10.64 to 18.47 & & -16.4 to 23.7 & \\
\hline SD & 0.226 & 8.8 & & 8.44 & & 13.1 & \\
\hline $95 \% \mathrm{CI}$ & & $-6.5 ; 3.3$ & & $-2.8 ; 6.5$ & & $-5.3 ; 8.6$ & \\
\hline & & & 0.35 & & 0.51 & & 0.77 \\
\hline
\end{tabular}

\begin{tabular}{|c|c|c|c|c|c|c|c|c|}
\hline \multirow{23}{*}{$\begin{array}{l}\text { Table } 3 \text { Changes in bone } \\
\text { mineral density (BMD) of the } \\
\text { distal femur around the revision } \\
\text { total knee arthroplasty (rTKA) }\end{array}$} & & $\begin{array}{l}\text { BMD }\left(\mathrm{g} / \mathrm{cm}^{2}\right) \\
\text { Postoperative }\end{array}$ & $\begin{array}{l}\Delta \text { BMD }(\%) \\
0-3 \text { months }\end{array}$ & $P$ value & $\begin{array}{l}\Delta \text { BMD }(\%) \\
0-6 \text { months }\end{array}$ & $P$ value & $\begin{array}{l}\Delta \text { BMD (\%) } \\
0-12 \text { months }\end{array}$ & $P$ value \\
\hline & \multicolumn{8}{|l|}{ ROI 1} \\
\hline & Mean & 0.848 & 4.5 & 0.03 & 6.0 & 0.01 & 3.4 & 0.07 \\
\hline & Range & $0.634-1.112$ & -5.3 to 16.4 & & -3.9 to 15.7 & & -3.4 to 10.8 & \\
\hline & SD & 0.153 & 5.9 & & 5.8 & & 4.9 & \\
\hline & $95 \% \mathrm{CI}$ & & $0.5 ; 8.5$ & & $2.1 ; 9.9$ & & $-0.3 ; 7.2$ & \\
\hline & \multicolumn{8}{|l|}{ ROI 2} \\
\hline & Mean & 1.014 & 3.1 & 0.06 & 4.1 & 0.03 & 3.4 & 0.12 \\
\hline & Range & $1.285-1.014$ & -5.0 to 9.6 & & -4.7 to 16.1 & & -7.7 to 14.4 & \\
\hline & SD & 0.193 & 4.7 & & 5.6 & & 5.7 & \\
\hline & $95 \% \mathrm{CI}$ & & $-0.1 ; 6.2$ & & $0.4 ; 7.9$ & & $-1.0 ; 7.8$ & \\
\hline & \multicolumn{8}{|l|}{ ROI 3} \\
\hline & Mean & 1.236 & 2.2 & 0.03 & 3.5 & 0.02 & 2.8 & 0.27 \\
\hline & Range & $0.718-1.657$ & -3.3 to 5.6 & & -1.6 to 11.9 & & -9.6 to 15.0 & \\
\hline & SD & 0.251 & 2.8 & & 4.0 & & 6.9 & \\
\hline & $95 \% \mathrm{CI}$ & & $0.3 ; 4.0$ & & $0.80 ; 6.1$ & & $-2.6-8.1$ & \\
\hline & \multicolumn{8}{|l|}{ ROI 4} \\
\hline & Mean & 0.998 & 3.4 & 0.01 & 4.7 & 0.00 & 4.0 & 0.01 \\
\hline & Range & $0.641-1.310$ & -0.8 to 10.3 & & $1.9-9.7$ & & -0.7 to 10 & \\
\hline & SD & 0.184 & 3.7 & & 2.9 & & 3.1 & \\
\hline & $95 \% \mathrm{CI}$ & & $0.9 ; 5.8$ & & $2.8 ; 6.6$ & & $1.5 ; 6.3$ & \\
\hline & \multicolumn{8}{|l|}{ ROI 5} \\
\hline & Mean & 1.276 & -0.7 & 0.63 & -0.8 & 0.42 & 0.4 & 0.84 \\
\hline$R O I$ region of interest, & Range & $0.640-1.988$ & -5.6 to 3.9 & & -5.3 to 3.9 & & -6.7 to 8.3 & \\
\hline$S D$ standard deviation, & SD & 0.352 & 3.7 & & 3.0 & & 4.8 & \\
\hline$P$ values Student's $t$ test & $95 \% \mathrm{CI}$ & & $-3.8 ; 2.4$ & & $-3.0 ; 1.4$ & & $-3.7 ; 4.4$ & \\
\hline
\end{tabular}

$R O I$ region of interest, $S D$ standard deviation, $C I$ confidence interval $P$ values Student's $t$ test and is described in Wolff's law [16]: bone remodels and models to adapt to altered mechanical loads (adaptive bone remodeling).

Prospective studies on BMD changes after THA report a tendency of decrease in BMD during the first year after surgery. The decreases are greatest in the proximal ROIs (calcar region), unrelated to the method of fixation, and range from $11.5 \%$ to $28 \%$. The decrease in BMD diminishes distally to the tip of the stem [17-22] or shows small gain in BMD [23-25] (Table 3).

Studies on BMD changes at the distal femur after TKA report decreases in BMD ranging from $2.6 \%$ to $36 \%$ at 
2 years of follow-up [4-7]. The bone loss is typically located behind the anterior flange of the femoral implant and reported to be caused by stress shielding. The ROI behind the anterior flange is located at the distal part of the femur, whereas the ROIs in this study are located at the more proximal parts of distal femoral shaft. Even though most studies on changes in BMD after TKA have shown loss of bone mineral with time [4-6], Petersen et al. [26] reported a significant increase $(6,1 \%)$ in BMD at the lateral tibia condyle 2 years after TKA with uncemented tibial components without hydroxyapatite. Initial temporary increases in BMD within the first operative year after TKA were seen in another study [27].

Patients participating in our study all suffered from failed TKAs that resulted in periods of reduced mobilization or long-term immobilization, e.g., patients undergoing two-stage revision surgery. Given the fact that immobilization and reduced mobility suppresses BMD [28], the increase in BMD seen in this study is probably the result of increased mobility and load on the extremity after implantation of a well-functioning rTKA, thus stimulating femoral bone-to-bone formation.

There are some limitations to our study. The effect of canal filling could not be evaluated, as all femoral stems were in tight press fit. Furthermore, we only evaluated a femur stem length of 100-mm and thus could not measure a possible effect of the stem length on the bone remodelling pattern. In addition, the effect of pre- or preoperative femoral bone loss on the postoperative changes in BMD could not be considered, as all cases were F2b. Finally, the study included only a small sample size, which makes the results less certain, and this should be kept in mind in the interpretation of the results.

Acknowledgments We thank laboratory technician Karen-Elisabeth Sønderlev for help with performing DEXA measurements. The DEXA scanner was donated by The Velux Foundation of 1981. Financial support was received from Maggie og Svend Fritzches Mindelegat, Zimmer, Nordic Medical Supply, and Hovedstadens Sygehusfællesskab (H:S).

\section{Conflict of interest None.}

Open Access This article is distributed under the terms of the Creative Commons Attribution Noncommercial License which permits any noncommercial use, distribution, and reproduction in any medium, provided the original author(s) and source are credited.

\section{References}

1. Jarvinen M, Kannus $P$ (1997) Injury of an extremity as a risk factor for the development of osteoporosis. J Bone Joint Surg Am 79(2):263-276

2. Mazess RB, Barden HS (1988) Measurements of bone by dualphoton absorptiometry (DPA) and dual-energy X-ray absorptiometry (DEXA). Ann Chir Gyn 77:197-203
3. Glüer CG, Stiger P, Selvidge R, Elliesen-Kliefoth K, Hayashi C, Genant HK (1990) Comperative assessment of dual-photon absorptiometry and dual-energy radiography. Radiology 174: 223-228

4. Karbowski A, Schwitalle M, Eckardt A, Heine J (1999) Periprosthetic bone remodeling after total knee arthroplasty:early assessment by dual energy X-ray absorptiometry. Arch Orthop Trauma Surg 119:324-326

5. Spittlehouse AJ, Getty CJ, Eastell R (1999) Measurement of bone mineral density by dual energy X-ray absorptiometry around an uncemented knee prosthesis. J Arthroplasty 14:957-963

6. Petersen MM, Olsen C, Lauritzen JB, Lund B (1995) Changes in bone mineral density of the distal femur following uncemented total knee arthroplasty. J Arthroplasty 10:7-11

7. Petersen MM, Lauritzen JB, Pedersen JG, Lund B (1996) Decreased bone density of the distal femur after uncemented knee arthroplasty. A 1-year follow-up of 29 knees. Acta Orthop Scand 67:339-344

8. Engh GA, Ammeen DJ (1999) Bone loss with revision total knee arthroplasty: defects classification and alternatives for reconstruction. Instr Course Lect 48:167-175

9. Engh GA, Ammeen DJ (1998) Classification and preoperative radiographic evaluation: knee. Orthop Clin North Am 29:205217

10. Insall JN, Dorr LD, Scott RD, Scott WN (1989) Rationale of The Knee Society clinical rating system. Clin Orthop 248:13-14

11. Gehrchen PM, Petersen MM (2008) Evaluation of a custom-made software for measurements of bone mineral density around prostethetic implants. Improved metal exclusion facility. Nordic Ortopedic Federation 54th Congress, Amsterdam, Holland, June $11-13$

12. Ghazavi MT, Stockley I, Yee G, Davis A, Gross AE (1997) Reconstruction of massive bone defects with allograft in revision total knee arthroplasty. J Bone Joint Surg Am 79(1):17-25

13. Engh GA, Ammeen DJ (2007) Use of structural allograft in revision total knee arthroplasty in knees with severe tibial bone loss. J Bone Joint Surg Am 89(12):2640-2647

14. Benjamin J, Engh G, Parsley B, Donaldson T, Coon T (2001) Morselized bone grafting of defects in revision total knee arthroplasty. Clin Orthop Relat Res 392:62-67

15. Van Lenthe GH, Willems MMM, Verdonschot N, de Waal Malefijt MC, Huiskes R (2002) Stemmed femoral knee prostheses. Acta Orthop Scand 73:630-637

16. Wolff J (1892) Das Gesetz der Transformation der Knochen. Hirschwald, Berlin

17. Digas G, Karrholm J (2009) Five-year DEXA study of 88 hips with cemented femoral stem. Int Orthop 33(6):1495-1500

18. Damborg F, Nissen N, Jorgensen HR, Abrahamsen B, Brixen K (2008) Changes in bone mineral density (BMD) around the cemented Exeter stem: a prospective study in 18 women with 5 years follow-up. Acta Orthop 79(4):494-498

19. Venesmaa PK, Kroger HP, Jurvelin JS, Miettinen HJ, Suomalainen OT, Alhava EM (2003) Periprosthetic bone loss after cemented total hip arthroplasty: a prospective 5-year dual energy radiographic absorptiometry study of 15 patients. Acta Orthop Scand 74(1):31-36

20. Wixson RL, Stulberg SD, Van Flandern GJ, Puri L (1997) Maintenance of proximal bone mass with an uncemented femoral stem analysis with dual-energy $\mathrm{x}$-ray absorptiometry. J Arthroplasty 12(4):365-372

21. Sabo D, Reiter A, Simank HG, Thomsen M, Lukoschek M, Ewerbeck V (1998) Periprosthetic mineralization around cementless total hip endoprosthesis: longitudinal study, cross-sectional study on titanium threaded acetabular cup, cementless Spotorno stem with DEXA. Calcif Tissue Int 62(2):177-182 
22. Nishii T, Sugano N, Masuhara K, Shibuya T, Ochi T, Tamura S (1997) Longitudinal evaluation of time related bone remodeling after cementless total hip arthroplasty. Clin Orthop Relat Res 339:121-131

23. Boden HS, Skoldenberg OG, Salemyr MO, Lundberg HJ, Adolphson PY (2006) Continuous bone loss around a tapered uncemented femoral stem: a long-term evaluation with DEXA. Acta Orthop 77(6):877-885

24. Skoldenberg OG, Boden HS, Salemyr MO, Ahl TE, Adolphson PY (2006) Periprosthetic proximal bone loss after uncemented hip arthroplasty is related to stem size: DXA measurements in 138 patients followed for 2-7 years. Acta Orthop 77(3):386-392

25. Trevisan C, Bigoni M, Randelli G, Marinoni EC, Peretti G, Ortolani S (1997) Periprosthetic bone density around fully hydroxyapatite coated femoral stem. Clin Orthop Relat Res 340:109-117

26. Petersen MM, Gehrchen PM, Østgaard SE, Nielsen PK, Lund B (2005) Effect of hydroxyapatite-coated tibial components on changes in bone mineral density of the proximal tibia after uncemented total knee arthroplasty. J Arthroplasty 20:516-520

27. Petersen MM, Nielsen PT, Lauritzen JB, Lund B (1995) Changes in bone mineral density of the proximal tibia following uncemented total knee arthroplasty. A 3-year follow-up of 25 knees. Acta Orthop Scand 66:513-516

28. Rittweger J, Winwood K, Seynnes O, de BM, Wilks D, Lea R et al (2006) Bone loss from the human distal tibia epiphysis during 24 days of unilateral lower limb suspension. J Physiol 577(Pt 1):331-337 